\title{
REVIEW
}

\section{ASSESSING THE METHODOLOGICAL QUALITY OF CLINICAL GUIDELINES FOR PREVENTING FALLS OF PATIENTS}

\author{
Kamila Majkusová1, Darja Jarošová2, Renáta Zeleníková2, Radka Kozáková ${ }^{2}$ \\ ${ }^{1}$ Municipal hospital Ostrava, Department of Nursing, Czech Republic \\ ${ }^{2}$ Depatment of Nursing and Midwifery, Faculty of Medicine, University of Ostrava, Czech Republic
}

Received August 2, 2016; Accepted October 4, 2016. Copyright: This is an open access article distributed under the terms of the Creative Commons Attribution International License (CC BY). http://creativecommons.org/licenses/by/4.0/

\begin{abstract}
Aim: The study aimed to assess the methodological quality of selected clinical practice guidelines (CPGs) for preventing risk of falling in adult patients in acute and long-term institutional care. Design: Descriptive study using qualitative research techniques. Methods: CPGs were systematically searched in databases of clinical guidelines, systematic reviews, electronic databases, and websites of organizations and professional societies, based on predefined criteria and keywords fo the period 2000-2015. After sorting and analysing 53 documents, the methodological quality of seven selected CPGs were assessed with the AGREE II generic instrument. Results: All CPGs obtained highest domain scores in the dimensions Clarity and Framework, and Purpose, while the lowest standardized scores were achieved by the Applicability and Editorial independence domains. The Rigor of development and Stakeholder Involvement domains achieved an average score. A total of three recommended guidelines showed high methodological quality: Falls. Assessment and prevention of falls in older people - 572 b., 84 \% (NICE, 2013); Preventing Falls and Harm From Falls in Older People. Best Practice Guidelines for Australian Hospitals - 556 b., $84 \%$ (ACSQHC, 2009); and Prevention of falls and fall injuries in the older adult - 559 b., $82 \%$ (RNAO, 2005). Conclusion: Assessing the methodological quality of clinical guidelines using the AGREE instrument is one of the key steps in the process of their adaptation for other socio-cultural and organizational conditions. It would be possible to adapt and use all of the three most highly-rated CPGs to reduce risk of falling of inpatients in the Czech organizational and socio-cultural context.
\end{abstract}

Keywords: prevention of patient falls, clinical practice guidelines, methodological quality, AGREE II instrument.

\section{Introduction}

For healthcare providers, issues of quality of care are becoming increasingly important. This is related to general trends in healthcare, development of medical technologies, and efforts to make the best use of limited funds (Seifert et al, 2008). Clinical practice guidelines (CPGs) are tools which help healthcare professionals to make clinical decisions. Their application leads to the enhancement of the quality of healthcare, and helps to decrease the risk of human error (Jarošová, Zeleníková, 2014). The common denominator of the various definitions of CPGs is: "... expert opinions based on scientific evidence in order to improve the quality and efficiency of health care..." (Field, Lohr, 1992; Keffer, 2001; McMaster et al., 2007; Qaseem et al., 2012). The development

Corresponding author: Kamila Majkusová, Municipal hospital Ostrava, Nemocnični 898/20A, Ostrava - Moravská Ostrava, Czech Republic; e-mail: kamila.majkusovamno@seznam.cz of recommended clinical guidelines is an area whose importance has significantly increased worldwide in the past twenty years.

There have been significant developments in methods of development, evaluation and implementation of best practices, and the institutions that are involved in their creation. The Development was initially idiosyncratic in various countries, but considerable effort has recently gone into unifying methodology and working more closely together at a national and international level (Suchý, Bednařík et al., 2012, s. 6). Efforts to develop CPGs at a European level have resulted in a European Commission proposal for the creation of recommended clinical guidelines Methodology of recommended clinical guidelines (Council of Europe, 2002), and in a general methodology for assessing the quality of CPG: the AGREE Instrument. The main incentive for international cooperation in the development of recommended guidelines was the establishment of the AGREE Collaboration in 1998, with the aim of creating common tools for assessing the 
methodological quality of CPGs (Zeleníková in Jarošová et al., 2015). Falls and injuries among the elderly are a serious problem in the area of public healthcare in all regions of the world, particularly due to the aging population (WHO, 2007). Falls of patients, especially the elderly, are the most frequently reported undesirable events in healthcare facilities. A higher incidence of falls is recorded in the acutely and chronically ill, hospitalized patients, and those in long-term institutional care (Nurmi, Luthje, 2002; Hitcho et al., 2004; Roudsari et al., 2005). Injuries caused by falls often complicate the treatment of the elderly, prolong hospital stays, and worsen the primary disease (Hitcho et al., 2004). National benchmarking, tracking falls in medical facilities in the Czech Republic since 2002, indicates that most falls in proportion to the number of hospitalized patients occur on long-term care wards $(7.6 \%)$, and internal medicine departments $(1.5 \%)$. Conversely, the lowest number of patient falls are recorded in surgical departments $(0.4 \%)$ (ČAS, 2008). Clinical guidelines could provide a systematic solution to the reduction of risk of falling in patients in institutional care, based on recommendations from evidence-based practice. It is possible to create completely new clinical guidelines, although this is time-consuming and very costly (Steinbrook, 2007). In recent years, a systematic approach of trans-contextual adaptation has been increasingly used, derived from existing clinical guidelines, proven in practice. One of the initial steps in the adaptation process is assessing the methodological quality of a CPG with the AGREE generic instrument during its creation (ADAPTE Collaboration, 2009).

\section{Aim}

The study aimed to assess the methodological quality of selected CPGs for preventing risk of falling in adult patients in acute and long-term institutional care with the AGREE II generic instrument.

\section{Methods}

\section{Design}

A descriptive study using qualitative research techniques.

\section{Eligibility criteria}

The search involved CPGs published between 20002015 focusing on prevention of falls of adult inpatients in acute and long-term institutional care. Additional criteria were: CPGs published in full version, including the methodology of their development; CPGs published in English; and CPGs freely available in an electronic (or printed) version. The elimination criteria were: CPGs focusing only on implementation; those focusing only on selected groups of patients (e.g., those with stroke, or osteoporosis); and recommended guidelines for preventing falls in patients living at home, or assisted living and social residential facilities.

\section{Sources}

CPGs for preventing falls were searched in electronic bibliographical databases: MEDLINE, CINAHL, and EBSCO; in databases of systematic overviews: Cochrane Collaboration, ProQuest, ScienceDirect, and Web of Knowledge; in databases of recommended guidelines: Guidelines International Network (G-I-N); and in databases of overviews and evidence-based practice provided by the Joanna Briggs Institute (JBI) and McMaster University. Further sources included websites of organizations and societies that develop CPGs: the Agency for healthcare Research and Quality (AHRQ), the National Institute for Health and Care Excellence (NICE), the Registered Nurses' Association of Ontario (RNAO), the Scottish Intercollegiate Guidelines Network (SIGN), the Royal College of Nursing (RCN), the National Guideline Clearinghouse (NGC), The Accident Compensation Corporation (ACC), the Australian Clinical Practice Guidelines Portal, the Ministry of Health Singapore, the National Health and Medical Research Council (NHMRC) in Australia, the New Zealand Guidelines Group (NHMRC), the Best Practice Advocacy Centre, New Zealand (BPAC), the Royal College of Nursing (RCN), the American Geriatrics Society (AGS), and the Australian Commission for Safety and Quality in Health Care (ACSQHC).

\section{Search}

Based on the objective of the study were used for search the following keywords: falls, prevention, elderly, hospital, guideline.

\section{Study selection and data analyses}

A total of 53 relevant documents were selected from the 9,213 results displayed after a search based on search strategy and pre-defined criteria in electronic libraries and databases. The documents were sorted according to criteria defined for inclusion or exclusion of CPGs in the study. Further sorting was performed to exclude duplicate and specifically targeted CPGs, and non-complex and outdated CPGs (Figure 1). The basic set for evaluation was compiled from seven foreign recommended clinical practice guidelines (Table 1). 
Table 1 List of the assessed CPGs for preventing falls of patients in institutional care

Prevention of falls (acute care). Health care protocol. Institute for Clinical Systems Improvement, USA, 2012. (AHRQ)

Prevention of falls and fall injuries in the older adult (2005), and supplement (2011), Canada. (RNAO)

Preventing falls in acut care. In Evidence-based geriatric nursing protocols for best practice, USA, 2012. (HIGN)

Falls and fall risk in the long-term care setting, USA, 2011. (AMDA)

Prevention of Falls in Hospitals and Long Term Care Institutions, Singapore, 2005. (MHS)

Preventing Falls and Harm From Falls in Older People. Best Practice Guidelines for Australian Hospitals, Australia, 2009. (ACSQHC)

Falls. Assessment and prevention of falls in older people, United Kingdom, 2013. (NICE)

The selected CPGs retrieved from electronic databases were individually assessed by four independent specialists (two nurses specializing in nursing care in gerontology and two academic workers specializing in nursing care) using a Czech version of the AGREE II instrument (Líčeník, Kurfürst, Ivanová, 2013). The Appraisal of Guidelines and Research and Evaluation (AGREE) is a validated generic instrument for assessing the methodological quality of CPGs. The AGREE instrument consists of 23 items organized within six domains (Scope and purpose, Stakeholder
Involvement, Rigor of Development, Clarity of presentation, Applicability, and Editorial Independence), each capturing a unique dimension of guideline quality. Each of the items was rated on a seven-point Likert scale (form 1 - strongly disagree to 7 - strongly agree). The more considerations taken into account in the guideline, the higher the score the guideline should receive on that item from the appraiser (from a total score range of 23 to 161 points).

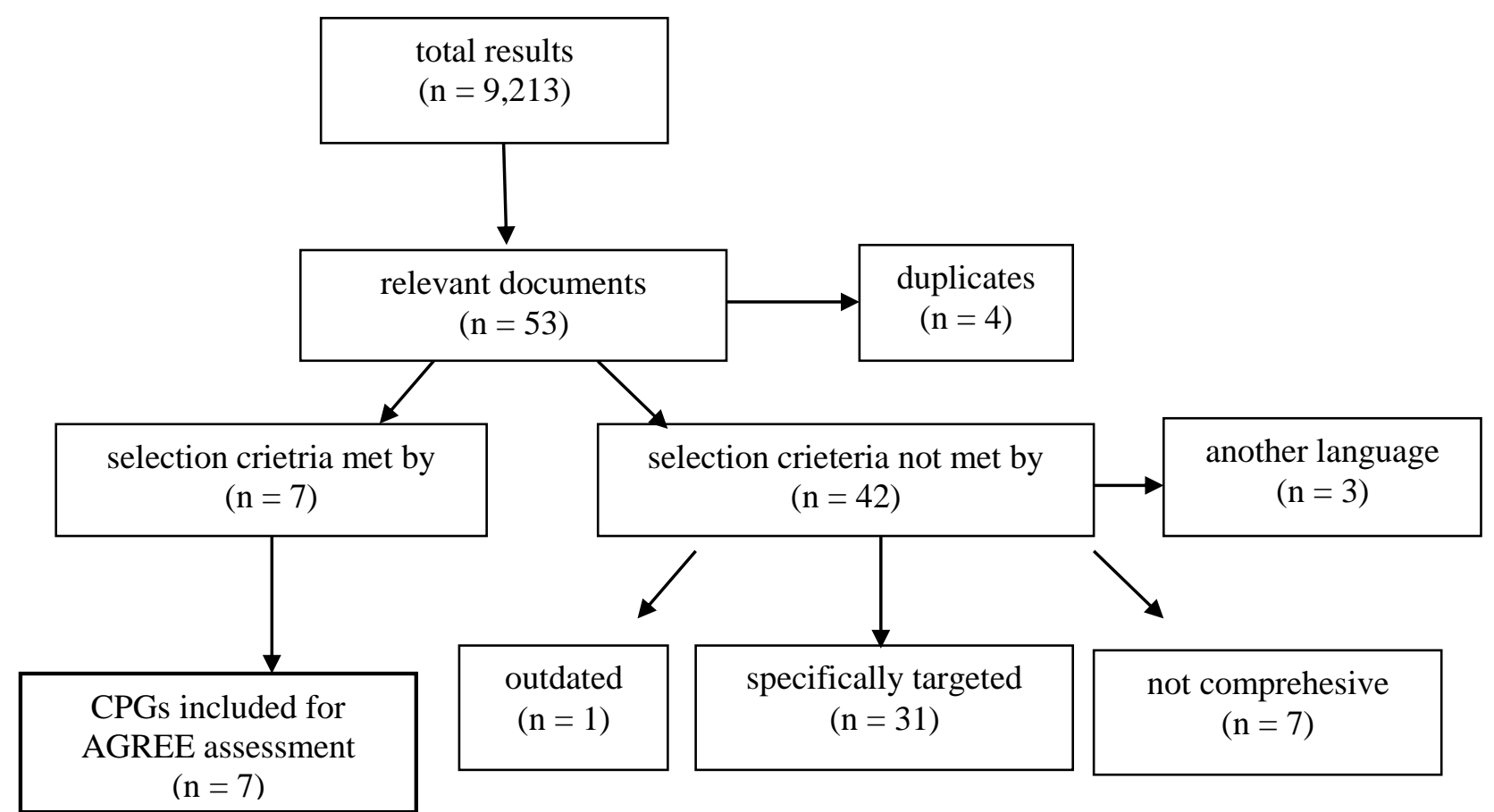

Figure 1 Flowchart for sorting CPGs for preventing falls of patients 
The scaled domain score for assessment of the methodological quality of CPGs is calculated for each of the six domains of AGREE II separately. The standardized domain score for each CPG is then calculated by summing up scores form all appraisers, and by scaling the total as a percentage of the maximum possible score for that domain: [(obtained score minus minimum possible score) / maximum possible score minus minimum possible score] x 100 . The modified AGREE II version was published in 2009 (AGREE 2009), and the Czech version of this instrument was published in 2013 (Líčeník, Kurfürst, Ivanová, 2013). The AGREE instrument evaluates the methodology of CPGs; it does not assess the clinical content of CPGs. To increase the reliability of the results, the CPGs should be assessed by at least two, and ideally four, independent appraisers (Brouwers et al., 2010).

\section{Results}

All evaluated CPGs obtained the highest domain score in the domains Clarity (84\%) and Scope and Purpose (77\%). The lowest scaled domain scores were obtained by the domains Applicability (51\%), and Editorial Independence (55\%). An average score was obtained by the domains Rigor of development (64\%) and Stakeholder involvement (63\%) (Table 2).

The third domain of the AGREE instrument - Rigor of Development - is considered crucial for the assessment of CPGs. The criteria for this domain assess the details and methods used to search for evidence, the utilization of sources, and data concerning references used for guideline formulation. Emphasis is placed on the search strategy, which should be as complex as possible, with an eye to the prevention of distortion, and detailed enough that it may be repeated, with similar results (AGREE, 2009). In this domain, the lowest scaled domain scores were obtained by the CPGs AMDA (33\%), AHRQ (38\%), and HIGN (47\%) (Figure 2). The most highly-rated domain in the majority of CPGs was the fourth domain: Clarity of Involvement, for which three CPGs obtained almost total scores (ACSQHC 99\%, MHS - 94\%, NICE - 92\%). Conversely, the worst rated CPG for this domain was AMDA (57\%). Clarity is defined in terms of providing a specific description of the options in specific situations which are suitable for usage in a given population group based on evidence (AGREE, 2009). The second most highly-rated domain overall was that of Scope and Purpose of CPG (77\%), focusing on the potential health impact of CPGs on the population of patients or individuals. Generally, the worst mean domain score was obtained for the domain Applicability (51\%), in which the support for implementation of guidelines, and the ease with which they can be applied in practice is assessed, including the possible existence of supplementary materials (AGREE, 2009). A very low score (4\%) was obtained in the Applicability domain by the HIGN and MHS guidelines, which either did not mention, or only briefly mentioned tools for implementation, and, additionally, failed to consider possible impacts on resources. HIGN did not contain criteria for monitoring or audit. Conversely, the NICE guidelines, which contained clearly defined features and tools for possible implementation, achieved the best scaled domain score (89\%) for this domain.

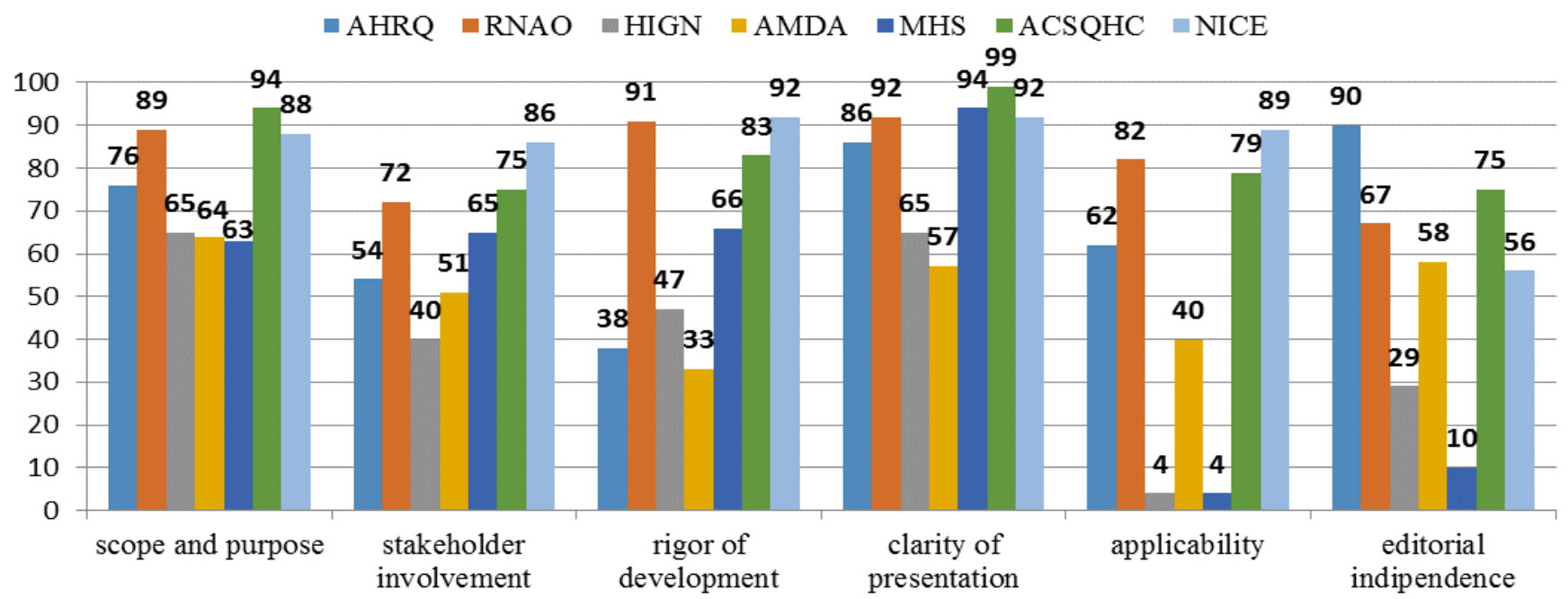

Figure 2 Assessment of selected CPGs for preventing falls according to AGREE II domains (\%) 
Table 2 Assessment of the methodological quality of CPGs for preventing falls using AGREE II instrument

\begin{tabular}{|c|c|c|c|c|c|c|c|}
\hline & $\begin{array}{c}\text { AHRQ } \\
\mathrm{n} / \%\end{array}$ & $\begin{array}{c}\text { RNAO } \\
\mathrm{n} / \%\end{array}$ & $\begin{array}{c}\text { HIGN } \\
\mathrm{n} / \%\end{array}$ & $\begin{array}{c}\text { AMDA } \\
\mathrm{n} / \%\end{array}$ & $\begin{array}{l}\text { MHS } \\
\mathrm{n} / \%\end{array}$ & $\begin{array}{c}\mathrm{ACSQHC} \\
\mathrm{n} / \%\end{array}$ & $\begin{array}{c}\text { NICE } \\
\mathrm{n} / \%\end{array}$ \\
\hline SCOPE AND PURPOSE & $67 / 76$ & 76/89 & $59 / 65$ & $58 / 64$ & $57 / 63$ & 80/94 & 75/88 \\
\hline $\begin{array}{l}\text { The overall objective(s) of the guideline is (are) specifically } \\
\text { described }\end{array}$ & 21 & 27 & 22 & 22 & 19 & 26 & 25 \\
\hline $\begin{array}{l}\text { The health question(s) covered by the guideline is (are) } \\
\text { specifically described }\end{array}$ & 25 & 23 & 18 & 17 & 21 & 26 & 25 \\
\hline $\begin{array}{l}\text { The population (patients, public, etc.) to whom the } \\
\text { guideline is meant to apply is specifically described }\end{array}$ & 21 & 26 & 19 & 19 & 17 & 28 & 25 \\
\hline STAKEHOLDER INVOLVEMENT & $51 / 54$ & $64 / 72$ & $41 / 40$ & 49/51 & $59 / 65$ & $66 / 75$ & 74/86 \\
\hline $\begin{array}{l}\text { The guideline development group includes individuals from } \\
\text { all relevant professional groups }\end{array}$ & 19 & 25 & 12 & 19 & 26 & 27 & 26 \\
\hline $\begin{array}{l}\text { The views and preferences of the target population } \\
\text { (patients, public, etc.) have been sought }\end{array}$ & 7 & 13 & 5 & 7 & 8 & 13 & 21 \\
\hline The target users of the guideline are clearly defined & 25 & 26 & 24 & 23 & 25 & 26 & 27 \\
\hline RIGOR OF DEVELOPMENT & $105 / 38$ & 206/91 & $123 / 47$ & $96 / 33$ & $159 / 66$ & 191/83 & 209/92 \\
\hline Systematic methods were used to search for evidence & 10 & 28 & 22 & 16 & 23 & 20 & 25 \\
\hline The criteria for selecting the evidence are clearly described & 11 & 28 & 14 & 10 & 24 & 26 & 27 \\
\hline $\begin{array}{l}\text { The strengths and limitations of the body of evidence are } \\
\text { clearly described }\end{array}$ & 10 & 26 & 9 & 8 & 21 & 23 & 28 \\
\hline $\begin{array}{l}\text { The methods for formulating the recommendations are } \\
\text { clearly described }\end{array}$ & 9 & 23 & 9 & 15 & 16 & 23 & 25 \\
\hline $\begin{array}{l}\text { The health benefits, side effects, and risks have been } \\
\text { considered in formulating the recommendations }\end{array}$ & 6 & 23 & 19 & 16 & 22 & 25 & 27 \\
\hline $\begin{array}{l}\text { There is an explicit link between the recommendations and } \\
\text { the supporting evidence }\end{array}$ & 22 & 28 & 21 & 6 & 28 & 28 & 25 \\
\hline $\begin{array}{l}\text { The guideline has been externally reviewed by experts prior } \\
\text { to its publication }\end{array}$ & 13 & 23 & 15 & 15 & 13 & 27 & 25 \\
\hline A procedure for updating the guideline is provided & 24 & 27 & 14 & 10 & 12 & 19 & 27 \\
\hline CLAI & 74/86 & 78/92 & $59 / 65$ & 53/57 & 80/94 & 83/99 & 78/92 \\
\hline The recommendations are specific and unambiguous & 22 & 27 & 23 & 22 & 27 & 28 & 25 \\
\hline $\begin{array}{l}\text { The different options for management of the condition or } \\
\text { health issue are clearly presented. }\end{array}$ & 23 & 23 & 19 & 12 & 26 & 27 & 26 \\
\hline $\begin{array}{l}\text { Key recommendations are easily identifiable. } \\
\text { APPLICABILITY }\end{array}$ & $\begin{array}{c}26 \\
\mathbf{7 5 / 6 2}\end{array}$ & $\begin{array}{c}28 \\
\mathbf{9 5 / 8 2}\end{array}$ & $\begin{array}{c}17 \\
20 / 4\end{array}$ & $\begin{array}{c}19 \\
\mathbf{5 4 / 4 0}\end{array}$ & $\begin{array}{c}27 \\
60 / 4\end{array}$ & $\begin{array}{c}28 \\
92 / 79\end{array}$ & $\begin{array}{c}27 \\
\mathbf{1 0 1 / 8 9}\end{array}$ \\
\hline $\begin{array}{l}\text { The guideline describes facilitators and barriers to its } \\
\text { application }\end{array}$ & 20 & 25 & 6 & 20 & 16 & 22 & 22 \\
\hline $\begin{array}{l}\text { The guideline provides advice and/or tools on how the } \\
\text { recommendations can be put into practice }\end{array}$ & 26 & 25 & 4 & 19 & 13 & 26 & 25 \\
\hline $\begin{array}{l}\text { The potential resource implications of applying the } \\
\text { recommendations have been considered }\end{array}$ & 4 & 22 & 4 & 6 & 6 & 27 & 26 \\
\hline $\begin{array}{l}\text { The guideline presents monitoring and/or auditing kriteria } \\
\text { EDITORIAL INDIPENDENCE }\end{array}$ & $\begin{array}{c}25 \\
\mathbf{5 1 / 9 0}\end{array}$ & $\begin{array}{c}23 \\
\mathbf{4 0 / 6 7}\end{array}$ & $\begin{array}{c}6 \\
22 / 29\end{array}$ & $\begin{array}{c}9 \\
36 / 58\end{array}$ & $\begin{array}{c}25 \\
13 / 10\end{array}$ & $\begin{array}{c}17 \\
44 / 75\end{array}$ & $\begin{array}{c}28 \\
\mathbf{3 5 / 5 6}\end{array}$ \\
\hline $\begin{array}{l}\text { The views of the funding body have not influenced the } \\
\text { content of the guideline }\end{array}$ & 25 & 21 & 10 & 19 & 7 & 23 & 13 \\
\hline $\begin{array}{l}\text { Competing interests of guideline development group } \\
\text { members have been recorded and addressed }\end{array}$ & 26 & 19 & 12 & 17 & 6 & 21 & 22 \\
\hline Total sum of assessment / percentage & $423 / 68$ & $559 / 82$ & $324 / 41$ & $346 / 51$ & $428 / 50$ & $556 / 84$ & $572 / 84$ \\
\hline
\end{tabular}

The ACSQHC guidelines (79\%) additionally contained independent informational materials with guidelines for individual user groups (nurses, doctors, patients, students, and carers), and also guidelines for those providing cleaning of departments. In the domain Stakeholder Involvement, the involvement of specialists in CPG development was assessed, with the exception of reviewers and representatives of the targeted population. The NICE guidelines achieved the highest scaled domain score obtained in this domain (86\%). On the other hand, the worst evaluation was achieved by the NHIG guidelines (40\%). The final domain evaluated using the AGREE instrument was the Editorial Independence domain. Specialists in this domain assessed resources and funding of CPG development, which should be 
independent of the content of specific CPGs. In addition, the objectivity of guideline authors, and their influence on the final wording of CPGs were assessed. The lowest assessment score was obtained by the CPGs MHS (10\%), and HIGN (29\%). On the other hand, the AHRQ guidelines (90\%), and ACSQHC guidelines $(75 \%)$ received the highest assessments. The final comparison of the methodological quality of all seven CPGs, their scaled domain scores, and mean percentage values, revealed the three best assessed CPGs in terms of methodological quality: Falls Assessment and prevention of falls in older people, edited in 2013, developed by the National Institute for Health and Care Excellence (NICE) (572 b.; 84\%); Preventing Falls and Harm From Falls in Older People. Best Practice Guidelines for Australian Hospitals, published in 2009 by the Australian Commission on Safety and Quality in Health Care (ACSQHC) (556 b.; 84\%); and Prevention of falls and fall injuries in the older adult, published in 2005, with a revised amendment in 2011, created by the Canadian organization of registered nurses, the Registered Nurses' Association of Ontario (RNAO) (559 b.; $82 \%)$.

\section{Discussion}

CPGs can improve the quality of care provided and thus demonstrate the importance of clinical practice based on evidence and its professional application in the clinical decision-making process and care management (Tingle, Foster, 2002). The differences in quality and inconsistencies in CPGs have led to the creation of an instrument assessing the methodology of CPG development. The AGREE instrument does not assess the professional content of CPGs, but provides internationally acknowledged criteria for assessing their reliability and validity (Zeleníková in Jarošová et al., 2015). However, according to Líčeník (2014), the weakness of such assessment is the subjective view of individual appraisers; this influence on results by subjective judgement can be reduced by requiring the involvement of a larger number of independent assessors, using a tool with a sufficient degree of validity and reliability. The First published evaluation of the quality of Czech practice guidelines was carried out between 20092012 in a study evaluating the quality of CPGs in the Czech Neurological Society CMS JEP (Czech Medical Society of Jana Evangelisty Purkyně), developed using the methodology of the National Reference Center. The assessed CPGs had a high standard of methodology, according to the authors, higher even than is typical of foreign studies. The authors stated the need to maintain the development of high-quality CPGs in the Czech Republic in the future through a comprehensive programme of creation, adaptation, implementation, and evaluation of CPGs, with an impact on the quality of healthcare (Líčeník et al., 2014). Assessment of the methodological quality of the seven selected CPGs was highly time-consuming. Distortion due to subjective evaluation of items by individual appraisers was minimized by the number of experts involved in the evaluation (two nurses specializing in nursing care in gerontology, with long experience in the prevention of patient falls, and two academic workers specializing in nursing care). The appraisers carried out the assessments individually and independently. If the appraisers diverged by two or more points while evaluating specific criteria, these items were addressed in discussion by a panel of experts. Different scoring was often the result of simply overlooking specific items. If the assessment score was very low, experts checked that the appraisers had not overlooked the necessary information in the CPG. During the assessment process, it was discovered that two CPGs (AMDA and HIGN) did not contain complex information (the complete methodology of their development was not available), which then influenced the final scale domain score in the Rigor of development domain, which, as a result, was very low.

The first assessed CPG was Prevention of falls (acute care). Health care protocol. Institute for Clinical Systems Improvement (AHRQ), in which the Rigor of Development, Stakeholder Involvement, and Applicability domains obtained the worst scores. Its greatest strength lay in its precise definition of specific clinical practice recommendations, tools for implementation, and plan for regular updates (every two years). On the other hand, a weakness of this recommended clinical practice (AHRQ), was its lack of information concerning methodology of development, with the authors and creators of the CPG mentioning it only in general terms. According to Zvolsky (2010), CPGs containing the methodology of their development are more transparent and are, therefore, from the user's perspective, more trustworthy.

The second recommended CPG: Prevention of falls and fall injuries in the older adult (2005), and supplement (RNAO), made use of the methodological instrument AGREE in its creation, another way in which it can be used (Líčeník, Kurfürst, Ivanová, 2013). The strength of this CPG was its clearly described methodology of development, planning, and implementation of revisions (again using the AGREE instrument). A weakness was the lack 
of information concerning the funding for its creation and any conflicts of interest of the authors. A further disadvantage of its possible usage in clinical practice is the fact that revised and updated interventions were published separately at the end of the text as a "supplement". If used in clinical practice, it would be necessary to incorporate the new interventions into the original document and discard interventions which have been shown to be obsolete according to the latest research (for example, the use of hip protectors in prevention of falls). Users of this CPG firstly receive an overview of the recommended interventions of 2005. However, it is not until the end of the document that it is revealed that some interventions are no longer recommended by experts.

During the evaluation process for the third evaluated CPG, Preventing falls in acute care. In Evidencebased geriatric nursing protocols for best practice (HIGN) using the AGREE instrument, it was discovered that the CPG did not contain any relevant information concerning its methodology of development, and that it was probably only a shortened version (consisting of only nine pages). The complete version of the CPG was not available. Certain essential information was missing in this version of the CPG (for example, a complete lack of information regarding its implementation); thus it was not possible to evaluate some items of the tool. Following assessment using the AGREE instrument, this CPG was definitively excluded from further assessment processes by a group of appraisers and, therefore, not recommended for further use. The CPG was intended only for acute care, whereas the requirement from the panel of experts was the possibility of using the CPG both in acute and longterm care.

During the evaluation process of the fourth recommended clinical practice: Falls and fall risk in the long-term care setting (AMDA), it was discovered that the CPG contained only a set of recommendations for preventing falls of patients in long-term institutional care. Moreover, there was a complete lack of information about sources used for CPG development. This CPG should have been discarded before comprehensive assessment. However, it is not always possible to retrieve certain information from a CPG until a thorough reading during the assessment process by means of the AGREE instrument.

Among the strengths of the fifth evaluated recommended clinical practice for preventing falls of patients: Prevention of Falls in Hospitals and Long Term Care Institutions, Singapore (MHS), were clear and precise definitions of interventions, with explicit references to the strength of evidence and the sources used. This CPG contained accurate information concerning measurement methodology and the effectiveness of its use in clinical practice. However, the CPG did not clearly state the sources of funding and methods for its implementation in clinical practice. Information regarding reviewers, methodology of development, and further ways of revision was completely missing. Despite the fact that it is highly recommended to conduct periodic revisions and updates of CPGs, this particular CPG had not been revised for as long as eight years at the time of our assessment.

The sixth evaluated CPG: Preventing Falls and Harm from Falls in Older People. Best Practice Guidelines for Australian Hospitals, Australia (ACSQHC) was very extensive in terms of content (236 pages). The Commission for the safety and quality of health care in Australia that created this CPG also defined recommendations for preventing falls among people living in the community and social institutions. This CPG did not include basic data regarding its implementation into clinical practice, criteria for assessment, and audit. On the other hand, it was the only one of the evaluated CPGs to contain a thorough description of after-fall management. Amendments to this CPG included informational materials for individual CPG users (doctors, non-physicians, management, and patients).

The Final evaluated recommended clinical guideline was the CPG Falls. Assessment and prevention offalls in older people (NICE). NICE is an independent organization of the Ministry of Health in Great Britain, which is responsible for the development of nationally recommended clinical guidelines for the provision of high quality healthcare. The highest-rated domains of this CPG were the Rigor of development, Clarity of presentation, and Applicability domains. Although this CPG demonstrated high quality of methodological development created using the AGREE instrument in 2013, it contained several limitations. The methodology of development and amendments were published separately from the actual CPG document. It was therefore necessary to conduct a complicated search for them on the organization's website. This could result in more frequent inaccuracies of assessment, which then require discussion and clarification by a panel of experts. A further disadvantage for users might also be the frequent references to already obsolete and outdated CPGs from 2004, whose target group were people living in the community - these recommendations were not included in the text of the new

CPG. 


\section{Conclusion}

Assessment of the methodological quality of clinical practice guidelines using the AGREE instrument is one of the fundamental steps for their further adaptation - adaptation to different socio-cultural and organizational conditions. The scaled domain scores for each guideline using the AGREE instrument are useful for comparison of assessed guidelines, and indicate whether the CPG should be used in clinical practice. The final decision is always made by experts and potential users of the recommended clinical guideline who carry out the evaluation, and is based on the context in which the AGREE instrument is used. In conclusion it would be possible to adapt and use all of the three highest-rated clinical guidelines - Falls. Assessment and prevention of falls in older people (NICE, 2013), Preventing Falls and Harm from Falls in Older People. Best Practice Guidelines for Australian Hospitals (ACSQHC, 2009), Prevention of falls and fall injuries in the older adult (RNAO, 2005) for preventing falls of inpatients in a Czech socio-cultural and health setting.

\section{Ethical aspects and conflict of interest}

All references to bibliographic sources have been cited. The authors declare that the study is without conflict of interest.

\section{Acknowledgement}

This work is dedicated by project IGA MZČR NT/14502 Development and implementation of clinical guidelines for preventing falls of inpatients and by project SGS 14/LF/2013 - Adaptation of clinical guidelines for preventing falls of patients in institutional care.

\section{Author contribution}

Manuscript draft, data collection, data analysis and interpretation (KM), conception and design, supervision, critical revision of the manuscript (DJ), evaluation of methodological quality of CPGs (KM, DJ, RZ, RK).

\section{References}

ADAPTE Collaboration. Guideline adaptation: a resource toolkit. Version 2.0. Prepared by the ADAPTE Collaboration, 2009. [cited 2014 Oct 30]. Available from: http://www.g-in.net/document-store/working-groups-

documents/adaptation/adapte-resource-toolkit-guidelineadaptation-2-0.pdf

AGREE II. Appraisal of guidelines for research \& evaluation II instrument. The AGREE next steps Consortium. May 2009. [cited 2015 Apr 26]. Available from: http://www.agreetrust.org/wp-

content/uploads/2013/10/AGREE-II-Users-Manual-and-23item-Instrument_2009_UPDATE_2013.pdf

Australian Commission on Safety and Quality in Health Care (ACSQHC). Preventing falls and harm from falls in older people: Best practice guidelines for Australian hospitals 2009. Sydney: ACSQHC; 2009. Available from: http://www.safetyandquality.gov.au/publications/preventing -falls-and-harm-from-falls-in-older-people-best-practiceguidelines-for-australian-hospitals-2009/

Brouwers MC, Kho ME, Browman GP, Burgers JS, Cluzeau F, Feder G, Fervers B, Graham ID, Grimshaw J, Hanna SE, Littlejohns P, Makarski J, Zitzelsberger L; AGREE Next Steps Consortium. AGREE II: advancing guideline development, reporting and evaluation in health care. Canadian Medical Association Journal. 2010; 182(18):E839842.

Council of Europe. Developing a metodology for drawing up guidelines on best medical practice. Recommenadation (2001)13 and explanatory memorandum. Zeitschrift für ärztliche Fortbildung und Qualitätssicherung. 2002;96(Suppl 3):5-59.

Česká asociace sester. Pády. (C) 2008 ČAS [cited 2015 Apr 26]. Available from: http://www.cnna.cz/narodni-indikatorykvality-pece/pady (in Czech)

Field MJ, Lohr KN. Guidelines for clinical practice. From development to use. Washington: National Academy; 1992.

Hitcho EB, Krauss MJ, Birge S, Claiborne Dunagan W, Fischer I, Johnson S, Nast PA, Costantinou E, Fraser VJ. Characteristics and circumstances of falls in a hospital setting: a prospective analysis. Journal of General Internal Medicine. 2004;19(7):732-739.

Jarošová D, Zeleníková R. Ošetřovatelství založené na důkazech. Evidence Based Nursing. 1. vyd. Praha: Grada Publishing; 2014. (in Czech)

Jarošová $\mathrm{D}$, Majkusová $\mathrm{K}$, Zeleníková $\mathrm{R}$, Kozáková $\mathrm{R}$. Klinické doporučené postupy $\mathrm{v}$ ošetřovatelství. 1. vyd. Praha: Grada Publishing; 2015. (in Czech)

Keffer JH. Guidelines and algorithms: perceptions of why when they are successful and how to improve them. Clinical Chemistry. 2001;47(8):1563-1572.

Ličeník R, Kliková K, Osinová D, Doubravská S, Ivanová K. Hodnocení kvality klinických doporučených postupů České neurologické společnosti ČLS JEP. Česká a Slovenská Neurologie a Neurochirurgie. 2014;77/110(1):64-69. (in Czech)

Líčeník R, Kurfürst P, Ivanová K. AGREE II: Nástroj pro hodnoceni doporučených postupư pro výzkum a evaluaci. Olomouc: Univerzita Palackého; 2013. (in Czech)

McMaster P, Rogers D, Kerr M, Spencer A. Getting guidelines to work in practice. Archives of Disease in Childhood. 2007;92(2):104-106.

National Institute for Health and Clinical Excelence. The guidelines manual. London: National Institute for Health and Clinical Excellence. 2012. [cited 2015 Nov 30]. Available from: https://www.nice.org.uk/process/pmg6/resources/theguidelines-manual-pdf-2007970804933

Nurmi I, Lüthje P. Incidence and costs of falls and fall injuries among elderly in institutional care. Scandinavian Journal of Primary Health Care. 2002;20(2):118-122.

Qaseem A, Forland F, Macbeth F, Ollenschläger G, Phillips S, van der Wees P; Board of Trustees of the Guidelines International Network. Guidelines International Network: 
toward international standards for clinical practice guidelines. Annals of Internal Medicine. 2012;156(7):525531.

Registered Nurses' Association of Ontario (RNAO). Prevention of falls and fall injuries in the older adult. Toronto, Canada: Registered Nurses' Association of Ontario; 2005 [cited 2015 Nov 30]. Available from: http://rnao.ca/sites/rnao-

ca/files/Prevention_of_Falls_and_Fall_Injuries_in_the_Olde r_Adult.pdf

Roudsari BS, Ebel BE, Corso PS, Molinari NA, Koepsell TD. The acute medical care costs of fall-related injuries among the U.S. older adults. Injury. 2005;36(11):13161322.

Seifer B, Bourek A, Forýtková L. Standardy léčebných postupu a kvalita ve zdravotni péči: manuál zvyšování kvality péče pro nemocnice, polikliniky, praktické lékaře a specialisty. 1. vyd. Praha: Verlag Dashöfer; 2008. (in Czech)
Steinbrook R. Guidance for guidelines. The New England Journal of Medicine. 2007;356(4):331-333.

Suchý M, Bednařík $\mathrm{J}$ et al. Klinické doporučené postupy v neurologii I. 1. vyd. Olomouc: Univerzita Palackého; 2012. (in Czech)

Tingle J, Foster Ch. Clinical guidelines: law, policy and practice. 1st ed. London: Routledge; 2002.

World Health Organization (WHO). WHO global report on falls prevention in older age. Geneva: World Health Organization; 2007.

Zeleníková R. Tvorba a adaptace klinických doporučených postupů. In: Jarošová D, Majkusová K, Zeleníková R, Kozáková R. Klinické doporučené postupy v ošetřovatelství. 1. vyd. Praha: Grada Publishing; 2015. p. 38-67. (in Czech) Zvolský M. The database of the catalogue of clinical practice guidelines published via internet in the Czech language - the current state. European Journal for Biomedical Informatics. 2010;6(1):83-89. 